\title{
KEMAMPUAN MENGAPRESIASIKAN UNSUR INSTRINSIK DAN EKSTRINSIK CERPEN "LAUT" KARYA NGURA PARSNA
}

\author{
Sartika $^{1}$, Nuraini Kasman ${ }^{2}$, dan A. Sadapotto ${ }^{3}$ \\ 1,2,3 Universitas Muhammadiyah Sidenreng Rappang \\ Jalan Angkatan 45 No 1A Lautang Salo Rappang \\ sartika_ek@gmail.com
}

\begin{abstract}
Abstrak: Kemampuan Mengapresiasikan Unsur Intrinsik dan Ekstrinsik Cerpen 'Laut' Karya Ngura Parsna. Penelitian ini bertujuan untuk mengetahui kemampuan siswa dalam mengapresiasi unsur instrinsik dan ekstrinsik Cerpen "Laut" Karya Ngura Parsna. Populasi penelitian ini adalah seluruh siswa kelas VII MTs. Muhammadiyah Baroko Kabupaten Enrekang yang berjumlah 36 orang, karena populasinya yang relatif kecil maka sampel yang digunakan adalah sampel populasi. Teknik pengumpulan data dalam penelitian ini adalah teknik dokumentasi dan teknik tes, sedangkan teknik analisis data yang digunakan adalah teknik statistik deskriptif, dalam bentuk persentase. Hasil penelitian menunjukkan bahwa siswa mampu mangapresiasi unsur intrinsik dan ekstrinsik cerpen. Hal tersebut dibuktikan dari hasil analisis data yang menunjukkan sebanyak 31 orang $(86,11 \%)$ yang memperoleh nilai 65 ke atas dan sebanyak 5 orang $(13,9 \%)$ yang memperoleh nilai kurang dari 65 .
\end{abstract}

Kata kunci: apresiasi, cerpen, unsur intrinsik, dan unsur ekstrinsik

\begin{abstract}
Ability to Appreciate The Intrinsic and Extrinsic Elements of 'Laut' Short Story by Ngura Parsna. This research aims to know the ability of students to appreciate the intrinsic and extrinsic elements in a short story. The population of this study is all students of grade VII MTs. Muhammadiyah Baroko Enrekang Regency which numbered 36 people, because the population is relatively small then the sample used is a sample of the population. The data collection techniques in this study are documentation techniques and test techniques, while the data analysis techniques used are descriptive statistical techniques, in percentage form. The results showed that students were able to appreciate the intrinsic and extrinsic elements of short stories. This is evidenced by the analysis of data that as many as 31 people $(86,11 \%)$ who score 65 and more and $5(13,9 \%)$ who score less than 65 .
\end{abstract}

Keyword: appreciation, short stories, intrinsic elements, and extrinsic elements

Karya sastra adalah cerita yang selalu berkutat dengan tokoh-tokoh fiksi yang diciptakan pengarangnya (Minderop, 2010). Pengajaran karya sastra tidak bisa mengabaikan pelatihan, bahkan di sekolah menengah pertama. Pembelajaran ini diharapkan dapat membekali siswa dengan pengetahuan sastra, sekaligus membuat karya sastra, memiliki sikap positif terhadap nilai sastra dan mampu mengembangkan pengetahuan dan keterampilan untuk minat lebih lanjut (Depdikbud, 1993).
Harapan tersebut dapat diwujudkan melalui pemajuan dan pengembangan sastra nasional, termasuk pengajaran sastra Indonesia. Pembinaan dan pengembangan tersebut dimaksudkan untuk meningkatkan kualitas pengajaran sastra sehingga dapat berfungsi sebagai cara yang efektif dan efisien dalam mendorong peserta didik agar: 1) dapat memiliki pengetahuan, keterampilan, memahami dan menghayati karya sastra Indonesia, 2) mampu memiliki kepekaan emosi, imajinatif, dan estetis terhadap nilai- 
nilai seni yang terkandung dalam unsur-unsur intrinsik penting dalam karya sastra Indonesia dan 3) memiliki kemampuan menanggapi dan mengevaluasi secara kritis unsur-unsur seni karya sastra (Depdikbud, 1993).

Selain fungsi di atas, juga diharapkan adanya upaya memajukan dan mengembangkan pengajaran sastra Indonesia sehingga menjadi pengajaran sastra yang berkembang secara efektif dan berkualitas. Pembelajaran sastra harus ditingkatkan kualitas dan kuantitasnya. Apresiasi sastra masih merupakan hal yang cukup rumit bagi siswa. Meskipun siswa merupakan sayuran dari generasi pengembang sastra yang baik, sastra juga merupakan tempat atau wadah yang memberikan kesempatan kepada orangorang terpelajar untuk melakukan refleksi atas pengejaran nilai-nilai dan kehidupan yang lebih intens.

Melalui kegiatan pembelajaran sastra Indonesia di sekolah menengah, guru dan masyarakat mengharapkan siswa memiliki wawasan sastra yang memadai, memiliki sikap positif terhadap sastra dan mampu mengembangkan wawasan, keterampilan, dan sikap lebih lanjut secara positif.

Berkaitan dengan hal tersebut, masalah kemampuan mengapresiasi sastra bagi siswa sekolah menengah sangat penting untuk diperdalam atau dikaji untuk mengidentifikasi faktor-faktor penyebab timbulnya masalah sastra. Melalui upaya-upaya tersebut, diharapkan dapat ditemukan langkah-langkah yang efektif dan efisien untuk meningkatkan kemampuan mahasiswa untuk lebih mengapresiasi sastra Indonesia.

\section{METODE}

\section{Variabel Penelitian}

Penelitian ini memiliki satu variabel yaitu kemampuan mengapresiasikan unsur ekstrinsik cerpen "Laut" karya Ngurah Parsna siswa kelas VII MTs. Muhammadiyah Baroko Kabupaten Enrekang.

\section{Populasi dan Sampel}

Populasi adalah keseluruhan subjek penelitian (Arikunto, 2012; Sudaryanto, 2000; Bugin, 2005). Populasi dalam penelitian ini sebanyak 36 orang, yang diambil dari jumlah seluruh siswa kelas VII MTs. Muhammadiyah
Baroko Kabupaten Enrekang. Sampel dalam penelitian ini sebanyak 36 orang, sehingga disebut sebagai penelitian populasi (Arikunto, 2012).

\section{Teknik Pengumpulan Data}

Teknik yang digunakan dalam pengumpulan data penelitian adalah tes dan dokumentasi. Teknik tes dilakukan mengukur keterampilan, pengetahuan, intelegensi, kemampuan atau bakat yang dimiliki oleh sampel. Teknik dokumentasi dilakukan dengan mengamati dan mencatat secara sistematik setiap gejala yang tampil dari objek penelitian (S. Margono, 1996).

\section{Teknik Analisis Data}

Penelitian ini digunakan teknik analisis statistik dalam bentuk persentase ( $85 \%$ keatas dengan paling rendah 65 dari skala penilaian $10-100$ ). Adapun rumus yang digunakan dalam pengolahan data sebagai berikut :

$$
N=\frac{\mathrm{SM}}{S I} \times 100
$$

\section{Keterangan}

$$
\begin{array}{ll}
\mathrm{N} & =\text { Nilai } \\
\mathrm{SM} & =\text { Skor mentah } \\
\mathrm{SI} & =\text { Skor Ideal } \\
& \quad P=\frac{\mathrm{X}}{\mathrm{N}} \times 100 \%
\end{array}
$$

Keterangan :

$$
\begin{array}{ll}
\mathrm{P} & =\text { Persentase } \\
\mathrm{X} & =\text { jumlah siswa yang memperoleh } \\
& \text { nilai } 65 \text { ke atas } \\
\mathrm{N} & =\text { Banyaknya siswa sampel }
\end{array}
$$

\section{HASIL DAN PEMBAHASAN}

Data yang akan disajikan berikut ini adalah data hasil belajar tentang anpresiasi unsur intrinsic dan ekstrinsik cerpen "Laut" karya Ngurah Parsna siswa kelas VII MTs. Muhammadiyah Baroko Kabupaten. Enrekang.

Tabel 1. Klasifikasi Nilai Siswa

\begin{tabular}{cccc}
\hline No. & Klasifikasi & Nilai & Frekuensi \\
\hline 1. & Sangat Baik & $86-100$ & 3 \\
\hline 2. & Baik & $71-85$ & 14 \\
\hline 3. & Sedang & $56-70$ & 14 \\
\hline 4. & Kurang & $41-55$ & 5 \\
\hline 5. & Sangat Kurang & $\leq 40$ & 0 \\
\hline \multicolumn{3}{c}{ Jumlah } & 36
\end{tabular}

Sumber : Hasil pengolahan data 
Tabel 2. Persentase Ketuntasan Belajar

\begin{tabular}{cccc}
\hline No & Nilai & Frekuensi & Persentase (\%) \\
\hline 1 & $\geq 65$ & 31 & 86,1 \\
\hline 2 & $<65$ & 5 & 13,9 \\
\hline \multicolumn{2}{l}{ Jumlah } & 36 & $100 \%$ \\
\hline
\end{tabular}

Sumber : diolah dari tabel 1

Berdasarkan tabel di atas menunjukan frekuensi dan persentase yang diperoleh data bahwa sebanyak 31 siswa $(86,1 \%)$ yang memperoleh nilai $\geq 65$ dan sebanyak 5 siswa $(13,9 \%)$ yang memeperoleh nilai $<65$.

Hal ini menunjukan bahwa siswa kelas VII MTs. Muhammadiyah Baroko Kabupaten Enrekang, mampu mengapresiasikan unsur intrinsik dan ekstrinsik cerpen. karena telah memenuhi kriteria yang ditetapkan yaitu minimal $85 \%$

\section{DAFTAR PUSTAKA}

Arikunto, S. 2012. Prosedur Penelitian Suatu Pendekatan Praktik. Jakarta: Rineka Cipta.

Bungin, Burhan. 2005. Metodologi Penelitian Kuantitatif. Jakarta: Kencana Prenada Media Group.

Depdikbud, GBPP. 1993. Mata Pelajaran Bahasa Indonesia. Jakarta: Balai Pustaka.

Herman J. Waluyo. 1987. Teori dan Apresiasi Puisi. Jakarta: Penerbit Erlangga.

Sudaryanto. 2000. Metodologi Penelitian Pendidikan dan Pengajaran Bahasa Jilid I. Yogyakarta: Universitas Negeri Yogyakarta.

Minderop, A. (2010). Psikologi Sastra: Karya, Metode, Teori, dan Contoh Kasus. Yayasan Pustaka Obor Indonesia. dengan nilai paling rendah 65 dari skala 10 100.

\section{PENUTUP}

Hasil penelitian ini menyimpulkan bahwa siswa kelas VII MTs. Muhammadiyah Baroko Kabupaten Enrekang mampu mengapresiasi unsur intrinsik dan ekstrinsik cerpen "Laut" karya Ngurah Parsna. Penulis menyarankan agar guru bidang studi Bahasa Indonesia dapat lebih meningkatkan cara belajar dan kreativitas siswa dalam pembelajaran sastra, khususnya unsur intrinsik dan ekstrinsik. 